\title{
Risk Factors of Preeclampsia in Anutapura General Hospital Palu City
}

\author{
Nur Rosmala ${ }^{1}$, Abd. Rahman ${ }^{2}$, Nila Sintya Dewi ${ }^{3}$, Nurul Fitria Aras $^{4}$, Pitriani ${ }^{\star, \dagger}, 5$ \\ ${ }^{1}$ Biostatistic, Family Planning and Demography Department \\ ${ }^{2}$ Health Promotion Department \\ ${ }^{3}$ Biostatistic, Family Planning and Demography Department \\ ${ }^{4}$ Biostatistic, Family Planning and Demography Department \\ ${ }^{5}$ Environmental Health Department Public Health Faculty Tadulako University, Palu City Indonesia
}

DOI:https://doi.org/10.15520/jcmro.v2i03.135

Accepted 12-03-2019; Received 21-02-2019; Publish Online 18-03-2019

\section{Reviewed By: Dr. Emmanuel Andres Department: Reviewer/CMRO}

\begin{abstract}
Preeclampsia is one of the main causes of maternal and fetal mortality and morbidity. The purpose of this study was to determine the risk factors for preeclampsia in pregnant women at Anutapura Hospital Palu. This study was observational analytic with a case control approach. The case subjects were pregnant women who experienced preeclampsia and the control group were pregnant women who did not experience preeclampsia. Case samples were 112 and control 112 with matching age. Sampling is done by purposive sampling technique. Data sources used secondary data, medical records 2017. The results showed that parity $(\mathrm{OR}=3,389$ and $\mathrm{CI}=1,936-5,934)$, complete antenatal care $(\mathrm{OR}=4,012$ and $\mathrm{CI}=2,293-7,020)$, history of hypertension (OR $=5,071$ and $\mathrm{CI}=2,819-9,120)$ is a risk factor for preeclampsia in pregnant women. To overcome the incidence of preeclampsia antenatal care is expected to be more active in providing information about pregnancies that are at high risk of developing preeclampsia in pregnant women.
\end{abstract}

Key words: Preeclampsia-Parity-Complete Antenatal Care-and History of Hypertension

\section{INTRODUCTION:}

Preeclampsia is a group of symptoms that specifically only appear during pregnancies over the age of 20 weeks (except for trophoblastic disease) and can be diagnosed by several criteria, namely an increase in blood pressure during pregnancy (systolic $\geq 140 \mathrm{mmHg}$ or diastolic proteinuria (3 0.3 gram protein for 24 hours or $\geq 30 \mathrm{mg} / \mathrm{dl}$ with urine reagent results $\geq \pm 1$ ). If symptoms of headache appear, visual disturbances, abdominal pain, low platelet value and kidney enzyme abnorma levels occur in pregnant women, preeclampsia should be suspected [1] .

Risk factors for preeclampsia include age, antenatal care examination, hereditary history, history of hypertension are risk factors that have been successfully identified to prevent the onset of preeclampsia. Death during childbirth is a major factor in women's mortality at the peak of their

\footnotetext{
* Corresponding author.

$\dagger$ Email: pitrianiarifinkl07@gmail.com
}

productivity [2] . One effort to reduce Perinatal Mortality Rate (AKP) due to preeclampsia is to reduce the incidence of preeclampsia. The incidence can be reduced through prevention, early observation and therapy [3] .

The results of the study [4] suggested that first pregnancy parity and parity $>3$ had 0.17 times more risk of developing preeclampsia than mothers with parity $2-3$. Parity in the mother is one factor in the occurrence of preeclampsia. The first parity is related to the lack of experience and knowledge of mothers in the care of pregnancy. One parity and high parity (more than three) is a parity at risk for preeclampsia. High parity causes excessive uterine stretching which causes excessive ischemia which can cause preeclampsia [5] .

To avoid disruption in pregnancy, pregnant women are required to do a good and regular antenatal care (ANC) examination. The purpose of ANC is to find out early on the existence of a problem or disorder and possible complications that occur during pregnancy such as the occurrence of preeclampsia [6] . According to the results of the study [7] that antenatal examination had a risk of 17.11 times the in- 


\section{Risk Factors of Preeclampsia in Anutapura General Hospital Palu City}

cidence of preeclampsia compared with respondents who did antenatal examinations. A complete antenatal care examination can prevent the development of preeclampsia, because one of the purposes of antenatal care is to recognize early complications or complications that occur during pregnancy.

Based on the annual report of the Anutapura Palu Hospital, the number of cases of preeclampsia from 2016 to 2017 has increased, in 2015 there were 36 cases, in 2016 there were 43 cases and in 2017 there were 112 cases of preeclampsia. This shows that there is still a high incidence of preeclampsia in pregnant women at Anutapura General Hospital, Palu. Meanwhile, based on the annual report book of RSUD Undata Palu the number of preeclampsia cases from 2015 to 2017 has decreased, where in 2015 there were 77 cases of preeclampsia, whereas in 2016 there were 19 cases of preeclampsia, and in 2017 there were only 7 cases of preeclampsia.

The handling and control of pregnancy in the hospital must be handled by a competent doctor, this is because mothers who have preeclampsia are included in very high risk conditions so they cannot be treated at the health center. The handling of preeclampsia in hospitals is also supported by the availability of complete health facilities compared to puskesmas whose health facilities are still limited. The handling of inappropriate preeclampsia can worsen the condition of the fetus and mother to cause death, therefore it is very important for pregnant women to get treatment in the hospital [8] . So from that the author wants to examine the risk factors for the incidence of preeclampsia in pregnant women at Anutapura Hospital Palu. This is because in the Anutapura Hospital Palu the incidence of preeclampsia is higher than in the RSUD Undata Palu.

\section{RESEARCH METHODS:}

This type of research is case-control which will be conducted in July 2018 until completion at Anutapura General Hospital (RSU), Palu. The study population was divided into two, namely the case population was all pregnant women who had preeclampsia while the control population were all pregnant women who did not experience preeclampsia. Sampling using total sampling technique. Data collection Secondary data obtained from medical records of patients who have complete data during 2017.

\section{RESULTS:}

1. Risk of Parity in Preeclampsia in Pregnant Women in Anutapura Palu Hospital in 2017.

The results of the parity risk analysis on the incidence of preeclampsia in pregnant women can be seen in Table 1 .

In Table 1 shows that the case respondents who experienced preeclampsia were more in mothers who had high risk parity 1 and $>3$ as many as 82 respondents (73.2\%). While more control respondents were mothers who had 23 low risk parity as many as 62 respondents (55.4\%). The results of the statistical test in Odd Ratio (OR) with Confidence Interval (CI) 95\% were obtained OR $=3.389(1,936$ $5,934)$ this means that respondents who had parity 1 and $>$ 3 risked 3,389 times greater preeclampsia than respondents which has 2-3 parity. Because the OR value $>1$, maternal parity is a risk factor for the incidence of preeclampsia in pregnant women

2. The Risk of Complete Antenatal Care Against Preeclampsia on Pregnant Women in Anutapura Palu Hospital in 2017.

The results of the risk analysis of complete antenatal care for the incidence of preeclampsia in pregnant women can be seen in Table 2

In Table 2 shows that case respondents who experienced preeclampsia were more likely to be mothers who did not have high risk antenatal care as many as 80 respondents $(71.4 \%)$. Whereas more control respondents were mothers who had complete low-risk antenatal care as many as 69 respondents $(61.6 \%)$.

The results of statistical tests obtained Odd Ratios (OR) with $95 \%$ Confidence Interval (OR) obtained OR $=4.012$ $(2,293-7,020)$ this means that respondents who did not complete antenatal care checks had a risk of 4,012 times more preeclampsia than respondents complete antenatal care examination. Because the OR value $>1$, the completeness of antenatal care is a risk factor for the incidence of preeclampsia in pregnant women.

3. Risk of Hypertension History of Preeclampsia in Pregnant Women at Anutapura Palu Hospital in 2017.

The results of hypertension risk analysis on the incidence of preeclampsia in pregnant women can be seen in Table 3

InTable 3 shows that case respondents who experienced preeclampsia were more likely to have a history of hypertension in mothers of 88 respondents $(78.6 \%)$. While more control respondents were mothers who did not have a history of hypertension as many as 64 respondents (57.1\%). The results of statistical tests in Odd Ratios (OR) with Confidence Interval (CI) $95 \%$ obtained OR $=5,071(2,819-9,120)$, this means that respondents who had a history of hypertension had a risk of 5,071 times greater preeclampsia than respondents who did not has a history of hypertension. Because the value of $\mathrm{OR}>1$, the history of hypertension in pregnant women is a risk factor for the incidence of preeclampsia. The OR value also shows the level of significance in this study, the history of hypertension has a significant relationship because the OR value passes one and number 1 is not between the upper values (2.819) and lower (9.120).

\section{DISCUSSION}

\section{Risk of Parity In The Incidence Of Preeclampsia In Pregnant Women:}

Parity in the mother is one factor in the occurrence of preeclampsia. One parity and high parity (more than three) is a parity at risk for preeclampsia. The statistical test results obtained OR $=3.389$ (CI 95\% 1,936-5,934), this means 
Table 1. RiskAnalysis of Parity Against Preeclampsia in Pregnant Women at Anutapura General Hospital Palu in 2017

\begin{tabular}{lllllll}
\hline & \multicolumn{3}{l}{ Preeklampsia } & \multicolumn{2}{l}{ Total } & OR \\
Paritas Mother & Case & \multicolumn{2}{c}{ Control } & & (CI 95\%) \\
& & $\%$ & & $\%$ & & \\
High Risk 1 dan $>3$ & 82 & 73,2 & 50 & 44,6 & 132 & \\
Low Risk 2-3 & 30 & 26,8 & 62 & 55,4 & 92 & $3,389(1,936-5,934)$ \\
Total & 112 & 100 & 112 & 100 & 224 & \\
\hline
\end{tabular}

Source: Primary Data, 2017

Table 2. Risk Analysis of Antenatal Care Completeness Against Preeclampsia in Pregnant Women in Anutapura Palu Hospital in 2017

\begin{tabular}{lllllll}
\hline & \multicolumn{3}{l}{ Preeklampsia } & & Total & OR \\
Completeness of ANC & Case & \multicolumn{1}{l}{ Control } & & (CI 95\%) \\
& & $\%$ & & $\%$ & & \\
Not Complete & 80 & 71,4 & 43 & 38,4 & 123 & \\
Complete & 32 & 28,6 & 69 & 61,6 & 101 & $4,012(2,293-7,020)$ \\
Total & 112 & 100 & 112 & 100 & 224 & \\
\hline
\end{tabular}

Source: Primary Data, 2017

Table 3. Analysis of the Risk of Hypertension History of Preeclampsia in Pregnant Women in Anutapura Palu Hospital in 2017

\begin{tabular}{lllllll}
\hline & \multicolumn{3}{l}{ Preeklampsia } & \multicolumn{2}{l}{ Total } & OR \\
History of Hypertension & \multicolumn{2}{l}{ Kasus } & Kontrol & & (CI 95\%) \\
& & $\%$ & & $\%$ & & \\
There is History & 88 & 78,6 & 48 & 42,9 & 136 & \\
No History & 24 & 21,4 & 64 & 57,1 & 88 & $5,071(2,819-9,120)$ \\
Total & 112 & 100 & 112 & 100 & 224 & \\
\hline
\end{tabular}

Source : Primary Data, 2017

that mothers who have risky parity $(1$ and $>3)$ are 3,389 times more at risk of having preeclampsia than mothers who have no risk of parity (2-3). The OR value also shows the level of significance in this study, OR $>1$ and number 1 so that parity has a significant relationship with the incidence of preeclampsia in pregnant women.

The first parity is related to the incidence of preeclampsia, due to a lack of experience and knowledge of mothers in the care of pregnancy. In addition, the mother is usually too busy taking care of the household so that she often experiences fatigue and not paying attention to fulfilling her nutrition. Mothers who have the first parity at a young age often experience stress in facing labor. Insufficient knowledge of the distance between pregnancies makes mothers unaware of the dangers of pregnancy and their fetus (Richters, 2008). Pregnancy risk mothers indicate that the reproductive organs function is not optimal or is not ready to face pregnancy, this will affect pregnancy and is very at risk of experiencing various pregnancy complications, one of which is preeclampsia.

Research conducted by [5], RSUD Wonosari that mothers with 4.7 times the risk of parity are at risk of developing preeclampsia compared to non-risky parity (2-3). The results of the study [7] said that there was a relationship between gravida status and the incidence of preeclampsia in pregnant women and primigravida respondents at risk of having a greater risk of developing preeclampsia com- pared to multigravida respondents. Besides that it is not in line with the research conducted by Langelo (2013) that there is no relationship between parity and the incidence of preeclampsia in pregnant women.

2. Risk of Complete Antenatal Care For The Incidence Of Preeclampsia In Pregnant Women:

Preeclampsia often appears at more than 20 weeks gestation, this is due to the active work of the placenta to drain nutrients for the fetus, causing an increase in blood pressure as a reaction to increase the metabolism of the body's organs. Regular and routine antenatal care to detect signs of preeclampsia is very important in preventing preeclampsia, because the older the gestational age, the higher the risk of developing eclampsia (Lestraningsih, 2018).

The statistical test results obtained OR $=4.012(95 \%$ CI 2,293-7,020), this means that mothers who do not have complete antenatal care risk 4,012 times more likely to experience preeclampsia than mothers who have complete antenatal care. The OR value also indicates the level of significance in which the $\mathrm{OR}>1$ and number 1 values do not exist between the upper $(2,293)$ and lower (7.020) values, so that the completeness of antenatal care has a significant relationship with the incidence of preeclampsia in pregnant women.

Antenatal care is very important for pregnant women because it can reduce pregnancy complications and also treat complications early. The results of Langelo et al. (2014) 
study showed that there was a significant relationship between prenatal care and the incidence of preeclampsia with a value of $\mathrm{p}=0,000$ and $\mathrm{OR}=2.72$ with a confidence level of $95 \% \mathrm{CI}=1.39-5.33$. In addition, it is not in line with the results of the study of Antono and Rahayu (2014) that the $\mathrm{p}$ value $=0.813(\mathrm{p}>0.05)$, so it was concluded that there was no significant relationship between antenatal care (ANC) and the incidence of preeclampsia.

Pregnant women who rarely check their pregnancy can increase the risk of complications of pregnancy. In antenatal care at each gestational age different obstetric interventions will be carried out according to needs, the mother who has been detected at the first high risk and her mother checks regularly, the mother's risk will be lower because the mother's pregnancy is monitored by health workers if further complications occur appropriate and not sudden interventions can be made. In contrast to pregnant women who do not check their pregnancies regularly, if the mother has been detected a high risk then the mother rarely checks the pregnancy so that if a new complication occurs the intervention will be sudden [9] .

\section{Risk of Hypertension History of Preeclampsia} in Pregnant Women:

History of hypertension is a mother who has had hypertension before becoming pregnant or before 20 weeks' gestation. Mothers who have a history of hypertension have a greater risk of developing preeclampsia, as well as increasing maternal and neonatal morbidity and mortality [10] . Hypertension in pregnancy is defined as systolic blood pressure $40140 \mathrm{mmHg}$ and / or diastolic blood pressure $\geq 90 \mathrm{mmHg}$.

Based on the results of research conducted at Anutapura Palu Hospital in 2017 that mothers who had a history of hypertension had more incidence of preeclampsia than mothers who did not have a history of hypertension. The results of statistical tests were OR $=5.071$ (95\% CI 2,819-9,120), this means that mothers who had a history of hypertension had a risk of 5,071 times greater preeclampsia than women who did not have a history of hypertension. OR values also indicate the level of significance in this study, OR $>1$ and number 1 are not between upper (2.819) and lower (9.120) values, so that the history of hypertension has a significant relationship with the incidence of preeclampsia in pregnant women.

The results of the analysis by Bere, Siaga, \& Fernandez (2017), there was a significant relationship between the risk factors for history of hypertension and the incidence of preeclampsia with $\mathrm{OR}=3.462(1,379-8,691)$ and $\mathrm{p}=$ 0.007 . This result is in line with the study [11], that there is a significant relationship between the history of the disease and the incidence of preeclampsia with a value of $\mathrm{p}=$ 0,000 and $\mathrm{OR}=3,877.15$ And supported by the results of research Bilano et al., (2014), that risk factors for hypertension have the relationship was significant and increased 3 times greater in preeclampsia. In addition, it is not in line with the results of the study [7], regarding the analysis of the relationship between the history of hypertension obtained that there was no significant relationship between the history of hypertension and the incidence of preeclampsia.
One of the risk factors for preeclampsia and associated history of hypertension is occupational factors. This is in accordance with the results of a study conducted by Gustri, Sitorus, \& Utama (2016), where maternal employment status also affects the incidence of preeclampsia, this can be seen from the distribution of respondents in cases of mothers who have household work that more risk get preeclampsia. There are not many people who don't work, so they can increase the incidence of hypertension (Kristansti, 2010). Julianti (2014) argues that mother's work increases the risk of pregnancy with preeclampsia 2 times compared to mothers who do not work.

Stress triggers the incidence of preeclampsia. According to Khayati and Veftisia (2018), stress is a risk factor for the occurrence of preeclampsia. Elsanti et al (2016) study, stress will increase the risk of the incidence of preeclampsia by 3.20 compared to mothers who are not stressed, this indicates that a pregnant woman who has a history of hypertension tends to experience the incidence of preeclampsia. This event can be minimized by conducting counseling for every pregnant woman to be able to know the danger signs that could occur during pregnancy, especially for pregnant women who have a history of hypertension beforehand in order to pay more attention to food, maternal and fetal health and diligently control pregnancy to health workers (Montalolu and Radjamuda, 2014).

\section{CONCLUSIONS:}

The conclusion of this study is parity, complete antenatal care, and a history of hypertension are risk factors for the incidence of preeclampsia. So that it is expected that mothers who have parity 1 or parity $>3$ should use and participate in family planning counseling to health services so that they can prevent and avoid the risk of preeclampsia. In addition, health workers can maximize socialization to pregnant women and recommend an increase in conducting ANC examinations to control maternal and fetal health, recommending to pay attention to the nutritional content of food for pregnant women.

Acknowledgement:

The authors grateful to all of those whom have had pleasure participated and supported this research

\section{REFERENCES}

[1] Setiawan, "Relationship between Parity and Contraception with Mild Preeclampsia at Jagir Health Center,"; 2016.

[2] J, Wibowo. Factors Affecting Maternal Death Case Study in the City of Surabaya,. J Wiyata. 2016;3(1):46-53.

[3] Situmorang, "Factors Associated with the Rsu Anutapura Palu Event,". J Healthy Tadulako. 2016;2(1):34-44.

[4] K, Fakhtiyah M. Maternal Determinants of Preeclampsia (Case Study in Tegal District, Central Java),. J Sudirman Nursing (The Sudirman J Nursing). 2016;2(1):17-23.

[5] Pratiwi I. The Relationship of Parity to Preeclampsia in Pregnant Women in Wonosari Hospital,. Aisyiyah College of Health. 2015; 
[6] Hendrati FELY. Relationship between Maternal Characteristics, ANC and Compliance with the Care of Pregnant Women with the Preeclampsia Occurrence,. J Berk Epidemiol. 2014;2(2012):216-226.

[7] S, Mardiana. Risk actors associated with Preeclampsia in Pregnant Women (Case study in Brebes District Hospital in 2014),. Unnes J Public Heal. 2016;5(2):90-99.

[8] Rozikhan, Risk Factors for Severe Preeclampsia in Dr. Hospital H. Soewondo Kendal. Semarang: Dipenogoro University; 2007.

[9] Manandhar A, L B, Chongstuvivatwong V, Geater. Antenatal Care and Severe Preeclampsia in Kathmandu Valley,. J Chitwan Med Coll. 2013;3(6):43-47.

[10] Astuti SF. Factors related to Pregnancy Preeclampsia in the South Tangerang City Pamulang Health Center Working Area 2014-2015,; 2015.

[11] Safitri. Relationship between Blood Pressure and Parity with Eclampsia in the RSUP NTB Maternity Room,. Media Bina Ilm. 2014;8(1). 